\title{
Maturity model for determining digitalization levels within different product lifecycle phases
}

\author{
Carina Siedler ${ }^{1}$ (D) Stephanie Dupont ${ }^{2} \cdot$ Mona Tafvizi Zavareh $^{3} \cdot$ Frank Zeihsel $^{4} \cdot$ Tobias Ehemann $^{3}$. \\ Chantal Sinnwell ${ }^{1}$. Jens C. Göbel ${ }^{4} \cdot$ Klaus J. Zink $^{2} \cdot$ Jan C. Aurich ${ }^{1}$
}

Received: 22 December 2020 / Accepted: 4 March 2021 / Published online: 18 March 2021

(c) The Author(s) 2021

\begin{abstract}
Maintaining pace with ongoing changes due to digitalization is challenging for manufacturing companies. For successful implementation of digitalization, manufacturing companies must consider their existing technical systems, organizational structures, and processes, as well as social aspects. With the support of a maturity model, a company-specific digitalization level can be evaluated to provide manufacturing companies with an initial insight into their particular status quo; this can serve as a starting point for future optimization and digitalization projects. Furthermore, the results of such an analysis allow objective comparison of different areas within the company and with competitors. In this paper, the "Integrierte Arbeitssystemgestaltung in digitalisierten Produktionsunternehmen" (InAsPro) maturity model is presented, which considers the Development, Production, and Assembly product lifecycle phases, as well as Aftersales, and assesses their digitalization level focusing on the four dimensions of Technology, Organization, Social Issues, and Corporate Strategy. The maturity model's rating scale distinguishes between four maturity levels. The results given by the InAsPro maturity model for an entire company are presented, along with those for each product lifecycle phase. Extensive descriptions for each specific maturity level are also provided.
\end{abstract}

Keywords Maturity model $\cdot$ Digitalization $\cdot$ Development $\cdot$ Production $\cdot$ Assembly $\cdot$ Aftersales

\section{Motivation and aim}

This paper presents the maturity model [1] established as part of the InAsPro project [2], which was developed to determine the digitalization level of a manufacturing company and thereby considers the requirements and properties of manufacturing companies. The basic maturity model was already partly published in german [1] and is here extended

Carina Siedler

carina.siedler@mv.uni-kl.de

1 Institute for Manufacturing Technology and Production Systems (FBK), P.O. Box 3049, 67653 Kaiserslautern, Germany

2 Institut Für Technologie Und Arbeit (Institute for Technology and Work), Trippstadter Straße 110, 67663 Kaiserslautern, Germany

3 Institute for Virtual Product Engineering (VPE), P.O. BOX 3049, 67653 Kaiserslautern, Germany

4 Enbiz Engineering and Business Solutions GmbH, Mozartstraße 25, 67655 Kaiserslautern, Germany by an extensive literature review, detailed identification of the research gap as well as a real-world application example in a small and medium-sized enterprise (SME). Additionally, the paper provides the "InAsPro maturity model guide", which contains all indicators as well as an extensive description of each stage.

In general, digitalization has been proclaimed as the strongest driver of industrial change and business advancement in the twenty-first century, leading to the Fourth Industrial Revolution [3]. However, a closer look at the organizational and process structures of manufacturing companies reveals that reality is less simple, because digitalization is implemented within all departments of a company and, therefore, corresponding interrelations exist. On the one hand, manufacturing comapnies in Germany have barely established a full coverage of the technologies and processes targeted by the Third Industrial Revolution; therefore, they have not yet founded bases for digitalization introduction [4]. On the other hand, recognition of a need for digitalization is always accompanied by the challenging task of determining the most suitable digital technologies to satisfy a 
given company's needs; these technologies must be chosen from among a large selection of often investment-intensive options [5]. Addressing these challenges is crucial, as only a focused and needs-based implementation of digital technologies can ensure a company's future business success; this should be accompanied by both transformation of the existing organizational structures and processes [6] and employee participation $[7,8]$.

Before starting the digitalization of a manufacturing company, it is necessary to understand the current digital state of the company $[9,10]$. A maturity model can be used to determine the digitalization level. The presented maturity model was developed for manufacturing companies and therefore, contemplates companywide aspects as well as certain criteria typical for the Development, Manufacturing, Assembly, and Aftersales areas. Moreover, the area of tension Technology, Organization, and Social as well as Corporate Strategy are featured. Not only the whole company can be assessed, also the digitalization level of different sizes of work systems can be determined. To improve the understanding of the maturity model, the procedure how it was created as well as the final maturity model are explained in detail. The maturity model results serve as a starting point for optimization and digitalization projects. Additionally, the maturity model is implemented in a software demonstrator, where the results can be stored and afterwards used as a benchmark both within the manufacturing company and across sectors.

\section{State of the art}

\subsection{Digitalization of manufacturing companies}

Digitization is the process of converting analog information into a digital format. In this format, the information consists of discrete data units that can be addressed, stored, processed, and managed separately with computing devices $[11,12]$. The term "digitization" is also applied to refer to the digital revolution, along with "digitalization" or "digital transformation". Thus, digitalization indicates a process of continuous change triggered by the growing usage of digital technologies [13] within the economy; this term is used throughout the present paper. Digital technologies are causing significant change along the value chain and creating strategic potential for companies and organizations. However, companies must attempt to manage the structural changes and organizational barriers that influence the positive and negative outcomes of this process [14].

Digitalization of manufacturing companies is implemented with the aim of horizontal integration through value networks, as well as vertical integration of all corporate levels [15]. This yields connected and integrated systems (information systems within and outside companies), objects (including products, devices, and machines), and people (workers, vendors, and users) within a company [16, 17]. Digitalization enables manufacturing companies to manage complex industrial processes [18] and introduces new possibilities, regarding e.g. efficiency, adaptivity and automation, thereby ensuring competitiveness and growth [19]. To achieve these goals, digital technologies must be implemented within all areas of a company [14]. Digital technologies are technologies that capture, process, transfer, and integrate analog information, e.g., data, documents, and procedures, into digital (virtual) values, which are then used in the work systems of manufacturing companies [20,21]. Examples are augmented reality [22], radio frequency identification [23], and data management systems [24]. However, as noted above, only implementation of digital technologies with consideration of the associated transformation of existing organizational structures and processes, as well as employee participation (so-called "digitalization solutions"), yields successful digitalization of manufacturing companies and their work systems.

\subsection{Product lifecycle phases}

To avoid isolated digitalization solutions, a valid, end-toend approach for all corresponding work systems is needed. Therefore, all lifecycle phases of a product must be considered. A product lifecycle consists of consecutive and interlinked steps [25] and begins with the product idea, followed by the design, process planning, product manufacturing, product usage and, finally, end of life (Fig. 1) [26]. To simplify matters, the product lifecycle is condensed to the four phases Development, Production, Assembly, and Aftersales phases within the project [27]. Nevertheless, it is essential to consider several phases in order to avoid isolated solutions and for a consistent digitalization.

The end-to-end approach supports exploitation of the effects of digitalization on other work systems [18]. For example, the quality assurance staff should be supported in performing test and measurement operations, as well as in responding to test results and correcting causes of incorrect measurements. This requires digital data preparation along several product lifecycle phases, such as product planning and product manufacturing.

The challenges of digitalization within the Development product lifecycle phase are, e.g., prospective determination of the production and the assembly work contents. Another challenge is engineering of smart products, i.e., cyber-physical systems (CPSs) that use and integrate Internet-based services to perform a required functionality [28].

Discrete parts are produced within the Production product lifecycle phase. The aim of (part) production is to produce individual parts for assembly or for delivery to customers [29]. The Assembly product lifecycle phase involves 


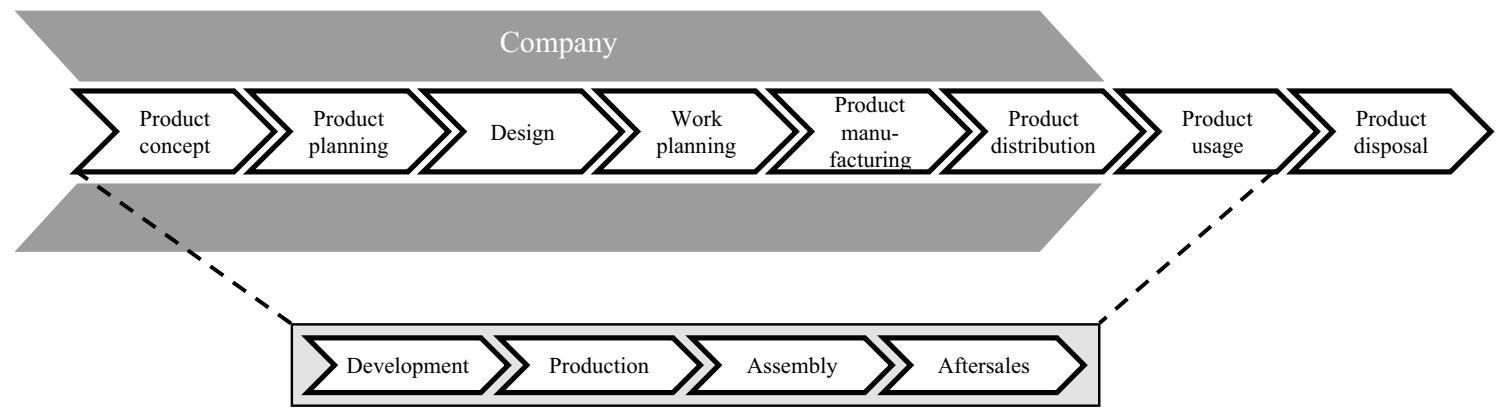

Fig. 1 Product lifecycle phases considered within InAsPro (own representation)

mounting of the individual parts to form modules or products [30]. As the tasks in the Production and Assembly phases differ, the material and information flow also differ. Therefore, it is necessary to analyze the process conditions in the first step before digitizing these product lifecycle phases [31]. Nevertheless, digitalization of the Production and Assembly product lifecycle phases can be achieved using CPSs, which are embedded systems connecting the physical environment and the virtual world [20]. Autonomous and cooperative elements and subsystems (e.g., CPSs), interconnected with each other and across the Production and Assembly phases form so-called "cyber-physical production systems (CPPSs)" [3].

The Aftersales product lifecycle phase contains services for manufactured goods and activities to support customers with goods usage, e.g., provision of predictive maintenance [32] and repair services as well as operating personnel training [33]. Digitalization expands the number and variety of aftersales activities and, also, customer contact [34]. Companies tend to offer not only a particular product, but also integrated solutions associated with the product [33], i.e., so-called "product-service systems (PSSs)" [35, 36]. They consist of technical product, complemented by different services of the product lifecycle [37]. PSSs are customeroriented solutions that yield increased product value and, therefore, increased customer value [38].

Based on the knowledge that implementation of specific digital technologies can also influence processes within all other product lifecycle phases, tools to assess a company's individual status with regard to digitalization must also consider all these phases to provide a comprehensive assessment. With the help of maturity models, a company's digitalization level can be determined and described.

\subsection{Maturity models}

Maturity models have a wide range of applications [39], but all models are structured similarly. In general, a maturity model is an instrument to measure the current status of an object of investigation, e.g., a person, a company, or a behavior within a specific area [40]. It consists of four basic elements: a predefined number of maturity levels with accompanying descriptions, indicators and its characteristics, and linkages between each maturity level and the corresponding characteristics and recommended activities based on the resulting maturity level. To apply the instrument, the user must select the characteristics of each indicator that best fit his or her company. By consolidating these aspects, a maturity level can be calculated and corresponding activities can be recommended [41].

In this study, a selection of existing maturity models were identified (Table 1) and subsequently analyzed regarding their suitability in terms of set requirements (see Sect. 3.2).

\section{Development of InAsPro maturity model}

The InAsPro maturity model was developed based on the existing maturity models (see Table 1) and through consolidation of the practical experiences of InAsPro project partners. The basic maturity model is explained and is extended by an extensive literature review, detailed identification of the research gap as well as a real application example by means of a small and medium-sized enterprise (SME). In the first developmental step, the goals and requirements were defined.

\subsection{Goals and requirements}

The maturity model was designed to measure the current state of a company's digital readiness on two levels: the company level and the level of the Development, Production, Assembly, and Aftersales product lifecycle phases. Differentiation of the phases is important as the digitalization of each single phase differs from those of the others. Furthermore, the maturity model aims to create results that can be used for companies of all sizes and as a benchmark across businesses [63]. Additionally, the InAsPro maturity model is intended to be compatible with other concepts developed through the 


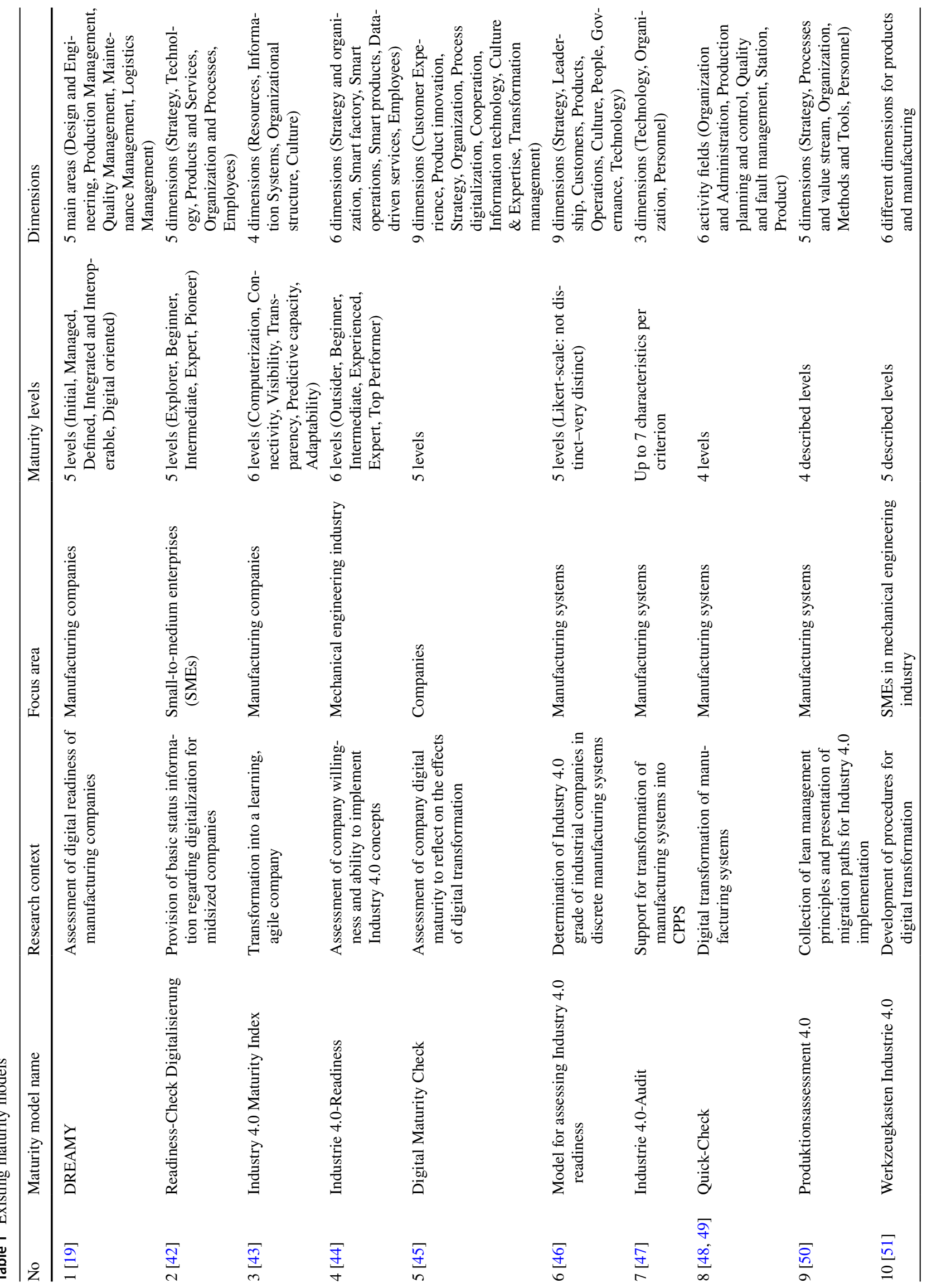




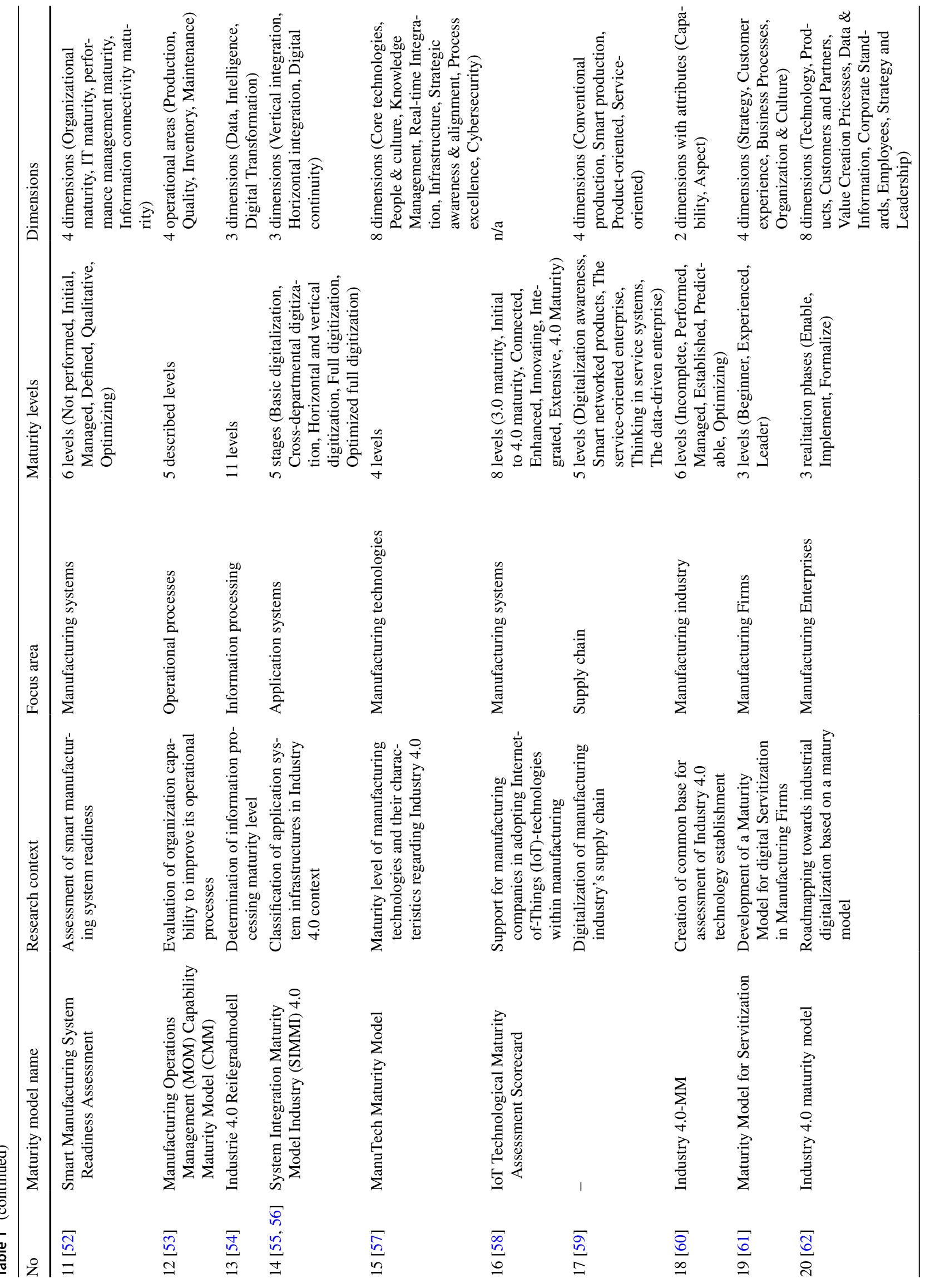


InAsPro project, such as the technology map [21, 64] and the transformation concept [27].

Besides the already mentioned objectives, the content goals were also considered. The developed maturity model equally considers criteria associated with the Social, Technology, and Organization dimensions based on the MenTechnology-Organization (MTO) Model [65]. Therefore, besides technological criteria, organizational (especially "Data Management" and "Cooperation and Collaboration") and social criteria (such as "Leadership," "Corporate Culture," and "Employee Development") must be considered. Additionally, it is necessary to consider the corporate strategy, as decisions on creation or maintenance of competitive advantages [66] are made on the company level.

As the maturity model considers the company level as well as the four product lifecycle phases, companywide aspects must be incorporated in the model, as well as aspects specific to each product lifecycle phase. However, the specific aspects that can be considered in the product lifecycle phase do not apply to all companies equally. For some companies, it is only necessary to evaluate small work systems, e.g., a machine or a manufacturing line, whereas for other companies, it is appropriate to equate the work system with a product lifecycle phase. Therefore, the maturity model must consider scalable work systems.

Furthermore, from the user perspective, the InAsPro maturity model must be easy to understand and use, and yield a comprehensible result that can be generated with minimal effort. For easier assessment of existing maturity models with regard to their attainment of the named goals, the above goals were translated into model requirements and specifications for the model architecture, as shown in Fig. 2.

\subsection{Identified research gap}

The reviewed maturity models (Table 1 ) were evaluated with regard to their fulfillment of the defined requirements (Fig. 2). The results are shown in Table 2.

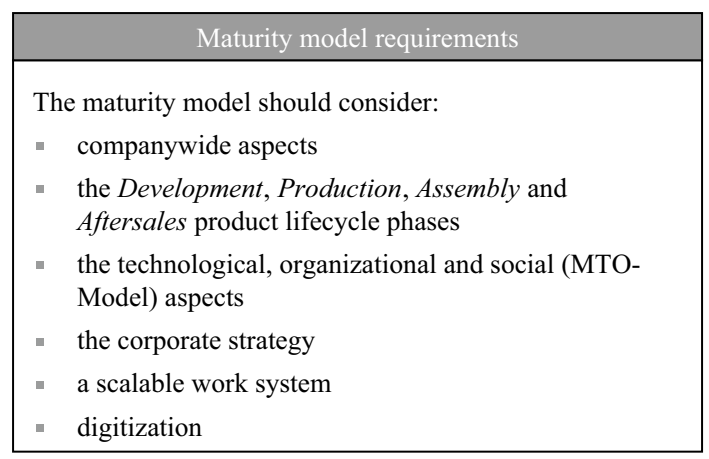

Fig. 2 Maturity model requirements [1]
- Companywide: Many of the considered maturity models focus on companywide aspects. These models aim to digitalize manufacturing or small and midsized companies (SME) and provide guidance during the transformation (e.g., [19, 42, 47, 49, 55, 60, 61]).

- Development: The Development product lifecycle phase is only considered by the maturity models presented in [42] and [43]. However, those models handle the product lifecycle phase in a general manner, e.g., if data transfer occurs between the Development phase and subsequent processes in the company [42].

- Production and Assembly: Digitalization of manufacturing systems is the main focus of maturity models (e.g., [46] [50-52, 58, 61, 62]). However, none of the existing models divide the manufacturing system into Production and Assembly phases; therefore, they do not consider potential differences between these two product lifecycle phases (see also Sect. 2.2).

- Aftersales: Only the models of [42, 43], and [44] consider the Aftersales product lifecycle phase. Those models contemplate, e.g., data-driven services [44], communicating or smart products $[42,44]$, or marketing channels [44].

- Technology: The Technology requirement is considered to different extents by almost all the maturity models. An exception is that of [54], which considers the Digital Transformation and Data and Intelligence dimensions but neglects technological aspects.

- Organization: Apart from the models of [53] and [54], all other maturity models take the Organization requirement into account.

- Social: Only a few maturity models include Social aspects (e.g., [45, 50, 62]).

- Corporate Strategy: Corporate Strategy is incorporated into most of the maturity models (e.g., [42],, [45, 46, 49, $50,57,59,61,62])$. However, the priority varies in terms of focus and level of detail. The maturity models consider the company's specific digitalization strategy for development of marketing channels, but also for creation of new business models.

- Scalable work system: The only maturity model suitable for a scalable work system is that of [43]. All other approaches neglect this requirement.

To summarize, the majority of the existing maturity models consider digitalization and focus on companywide aspects, especially technological, organizational, and social ones. Furthermore, the approaches employed by these models concentrate on digitalization of manufacturing systems. Only a few models also consider the corporate strategy and further product lifecycle phases, e.g., Development or Aftersales. Additionally, none of the identified models divide the 


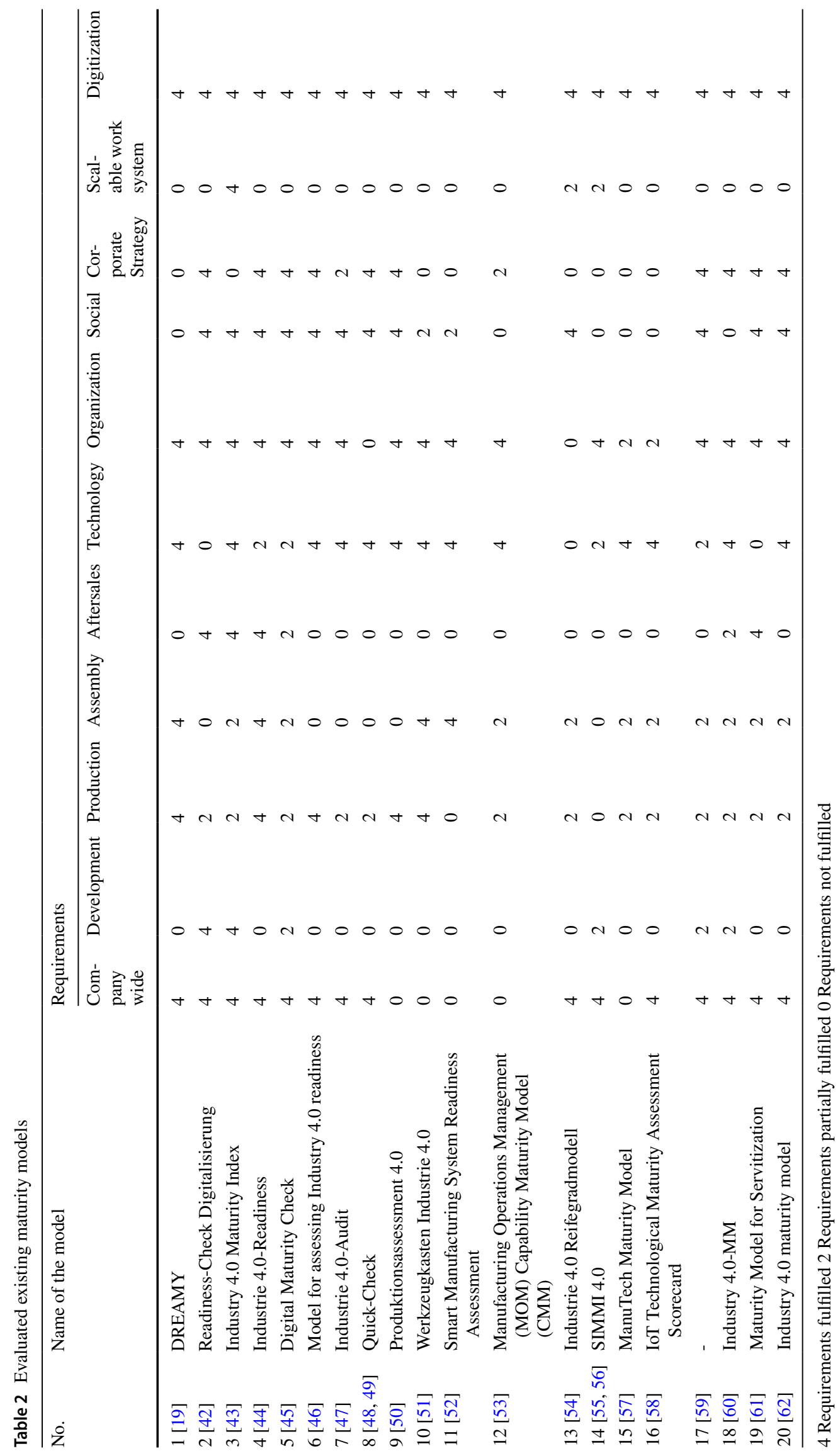


manufacturing area into production and assembly (see also, Sect. 2.2). As mentioned previously, a scalable work system must be taken as an object of investigation; however, this aspect is also neglected by the existing approaches. According to the above evaluation, none of the existing maturity models can fulfill all requirements to a satisfying extent. Consequently, a new maturity model must be developed.

\subsection{Development procedure}

For the structural design and development of the InAsPro maturity model, the methodological studies of de Briun [67], Becker [68], Akkasoglu [69], and Kübel [70] were considered. Those authors attempted to structure and simplify development of maturity models. By combining those guidelines, the development procedure for the InAsPro maturity model was defined. Figure 3 presents this procedure. First, preparation for development of the maturity model was conducted (Sects. 3.1 and 3.2). This was followed by the development (Sects. 3.4, 3.5) and application (Sect. 4) phases.

\subsection{Description of maturity levels}

The InAsPro maturity model consists of four maturity levels: Explorer, Beginner, Intermediate, and Expert. These levels and their value ranges are shown in Fig. 4. Here, $M L_{\text {total }}$ describes the total maturity level as regards digitalization of the company and is calculated by obtaining the arithmetic mean of the achieved maturity level of the four product lifecycle phases and the Corporate Level (see also Sect. 3.5). Additionally, for the Corporate Level as well as for each product lifecycle phase, every maturity level is defined with their characterizing aspects. These are, e.g., IT system design, development and manufacturing of smart products, as well as real-time data collection. This allows a detailed description of each product lifecycle phase and its individual maturity level. Hence, the user receives a comprehensive explanation of the calculated maturity level as well as the individual product lifecycle phases in which the user is interested. The four maturity levels are defined in Fig. 4 and the $M L_{\text {total }}$ values allocated to each level are shown. Additionally, for each product lifecycle phase, exemplary characteristics for each maturity level are presented.

The calculation of the digitization maturity level follows the structure of the model. Not only for each product lifecycle phase and for the corporate level an individual maturity level is calculated, also for each dimension and criterion. This enables companies to compare the digitalization degree of different dimensions as well as product lifecycle phases in more detail.

Starting with the value of each criterion (e.g. IT-system design or Data management), each criterion digitization degree $\left(D D_{\text {criterion }}\right)$ can be calculated through the mean of the belonging indicator values $\left(i v_{n}\right)$ depending on the total number of rated indicators $N \in\{1,2,3, \ldots\}$

$D D_{\text {criterion }}=(1 / N) \sum_{n=1}^{N} i v_{n}$.

If the user does not evaluate an indicator (e.g. networking along the value chain or data evaluation), this missing value is not considered within the calculation and therefore it does not change the resulting dimension maturity level $\left(M L_{\text {Dimension }}\right)$. The maturity level of the dimensions Technology, Organization, Social and Strategy can be calculated through the mean of the belonging criterion digitization degree $\left(D D_{\text {criterionk }}\right)$ depending on the total number of rated criteria $K \in\{1,2,3, \ldots\}$ :

$M L_{\text {Dimension }}=(1 / K) \sum_{k=1}^{K} D D_{\text {criterionk }}$.

For each of the product lifecycle phases Development, Production, Assembly and Aftersales as well as the corporate level, the digitization maturity levels for all dimensions are calculated. To receive the maturity level for each product lifecycle phase $\left(M L_{p l p}\right)$ and the Corporate level $\left(M L_{c l}\right)$, the mean of the calculated dimension maturity

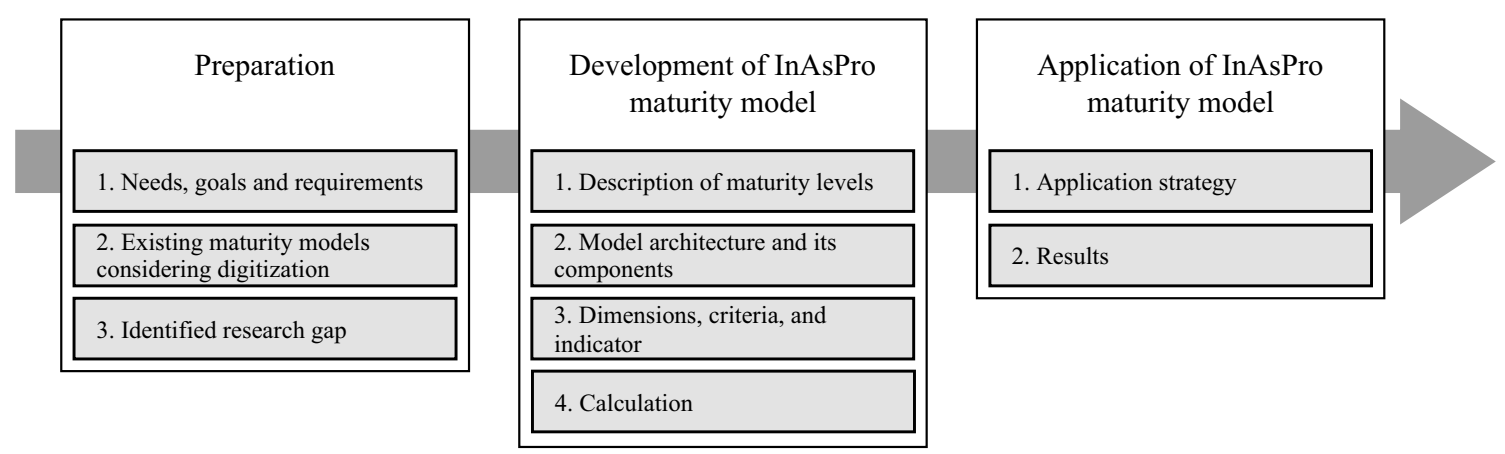

Fig. 3 Developmental procedure for digitalization maturity model 


\begin{tabular}{|c|c|c|c|c|}
\hline & Explorer & Beginner & Intermediate & Expert \\
\hline $\begin{array}{c}\text { Overall } \\
\text { description } \\
\text { of maturity } \\
\text { levels }\end{array}$ & $\begin{array}{l}\text { The company has limited } \\
\text { digitalization. }\end{array}$ & $\begin{array}{l}\text { Digitalization is the focus of } \\
\text { only some company divisions } \\
\text { and their linkage is rare. }\end{array}$ & $\begin{array}{l}\text { Digitalization is the focus of } \\
\text { most company divisions, which } \\
\text { are mostly horizontally and } \\
\text { vertically linked. The } \\
\text { digitalization mindset is } \\
\text { enshrined within the corporate } \\
\text { culture. }\end{array}$ & $\begin{array}{l}\text { Digitalization is fully } \\
\text { implemented within the } \\
\text { company. The divisions are all } \\
\text { horizontally and vertically } \\
\text { linked. Furthermore, } \\
\text { digitalization is actively } \\
\text { implemented and fully } \\
\text { enshrined within the corporate } \\
\text { culture and strategy. }\end{array}$ \\
\hline $\mathrm{ML}_{\text {total }}$ value & $1,0<M L_{\text {total }}<1,4$ & $1,5<M L_{\text {total }}<2,4$ & $2,5<M L_{\text {total }}<3,4$ & $3,5<M L_{\text {total }}<4,0$ \\
\hline
\end{tabular}

\begin{tabular}{|c|c|c|c|c|}
\hline $\begin{array}{c}\text { Corporate } \\
\text { level }\end{array}$ & $\begin{array}{ll}\text { - } & \text { Rarely interlinked IT systems } \\
\text { Data are stored in individual } \\
\text { formats } \\
\text { - } \\
\text { A digitalization mindset is } \\
\text { not embedded } \\
\text { - } \begin{array}{l}\text { No digitalization-oriented } \\
\text { strategy is available } \\
\text {... }\end{array}\end{array}$ & $\begin{array}{l}\text { - Some IT systems are } \\
\text { interlinked } \\
\text { - } \begin{array}{l}\text { Data can be converted into } \\
\text { standard formats }\end{array} \\
\text { - A digitalization mindset is to } \\
\text { some extent embedded } \\
\text { - A digitalization strategy is } \\
\text { planned } \\
\text {... }\end{array}$ & $\begin{array}{ll}\text { - } & \text { Most IT systems are } \\
\text { interlinked } \\
\text { - } \\
\text { Data are stored in } \\
\text { standardized formats } \\
\text { - } & \text { A digitalization mindset is } \\
\text { mainly embedded } \\
\text { - } \\
\text { A digitalization strategy is } \\
\text { under development } \\
\text {... }\end{array}$ & $\begin{array}{l}\text { - } \quad \text { Rarely interlinked IT systems } \\
\text { Data are stored format- } \\
\text { independant } \\
\text { - } \quad \text { A digitalization mindset is } \\
\text { fully embedded } \\
\text { - A digitalization strategy is } \\
\text { implemented } \\
\quad \ldots\end{array}$ \\
\hline Development & 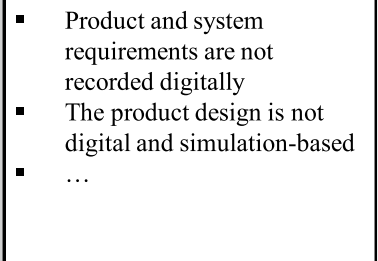 & $\begin{array}{l}\text { - Product and system } \\
\text { requirements are derived and } \\
\text { stored on a document-based } \\
\text { basis } \\
\text { - The product design is } \\
\text { partially digital and } \\
\text { simulation-based } \\
\text {... }\end{array}$ & 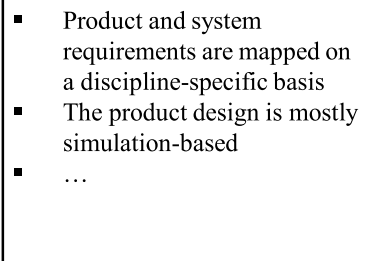 & 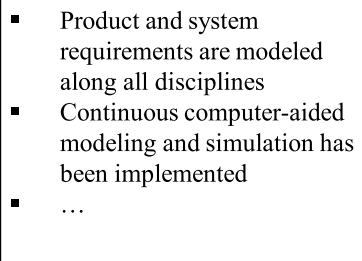 \\
\hline Production & $\begin{array}{l}\text { - Machinery and equipment in } \\
\text { the manufacturing process } \\
\text { are incapable of } \\
\text { communication } \\
\text { - The production planning and } \\
\text { control are performed } \\
\text { exclusively manually } \\
\text {... }\end{array}$ & 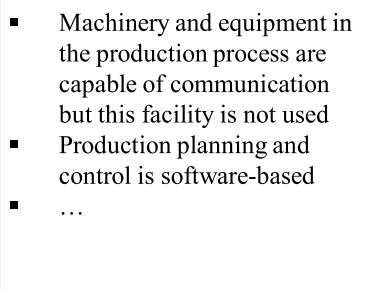 & $\begin{array}{l}\text { Machinery and equipment in } \\
\text { the production process are } \\
\text { capable of communication } \\
\text { but this facility is only } \\
\text { partially used } \\
\text { The production planning and } \\
\text { control are performed by } \\
\text { integrated systems, e.g., ERP } \\
\text { systems }\end{array}$ & $\begin{array}{l}\text { Machinery and equipment in } \\
\text { the production process are } \\
\text { capable of communication, } \\
\text { are fully networked, and this } \\
\text { facility is used } \\
\text { The production planning and } \\
\text { control is implemented } \\
\text { through digital planning } \\
\text { (digital twinning) }\end{array}$ \\
\hline Assembly & 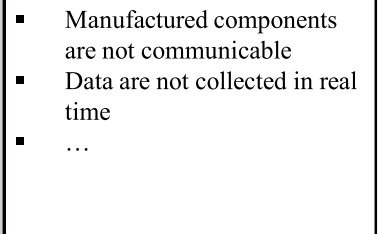 & $\begin{array}{l}\text { - Individual manufactured } \\
\text { components are capable of } \\
\text { communication } \\
\text { - Data are sometimes collected } \\
\text { in real time } \\
\text {-... }\end{array}$ & $\begin{array}{l}\text { - A large portion of the } \\
\text { manufactured components } \\
\text { are capable of } \\
\text { communication } \\
\text { - } \begin{array}{l}\text { Data are mostly collected in } \\
\text { real time } \\
\text {-.. }\end{array}\end{array}$ & $\begin{array}{ll}\text { - } & \text { All manufactured } \\
\text { components are } \\
\text { communicable (smart } \\
\text { products) } \\
\text { - } \\
\text { Data are collected } \\
\text { completely in real time } \\
\text {... }\end{array}$ \\
\hline Aftersales & $\begin{array}{l}\text { - Product maintenance is } \\
\text { performed at customer } \\
\text { locations } \\
\text { - } \begin{array}{l}\text { Product and customer data } \\
\text { are not collected and } \\
\text { therefore not evaluated } \\
\text {... }\end{array}\end{array}$ & 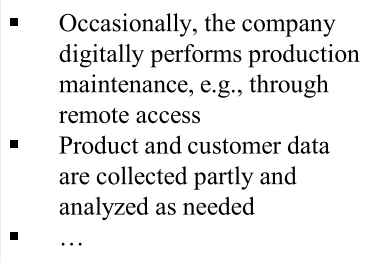 & $\begin{array}{ll}\text { - } & \text { The company predominantly } \\
\text { performs product } \\
\text { maintenance digitally } \\
\text { - } \\
\text { Product and customer data } \\
\text { are collected at intervals and } \\
\text { subjected to an automatic } \\
\text { analysis } \\
\quad \ldots\end{array}$ & 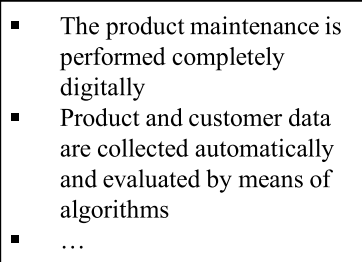 \\
\hline
\end{tabular}

Fig. 4 Description of company maturity levels and exemplary characteristics of each product lifecycle phase [1] 
levels is taken depending on the total number of rated dimensions $M \in\{1,2,3,4\}$ :

$M L_{c l}=M L_{p l p}=\left(\frac{1}{M}\right) \sum_{m=1}^{M} M L_{\text {Dimensionm }}$.

Finally, the total maturity level $\left(M L_{\text {total }}\right)$ over all product lifecycle phases and the companywide aspects can be determined. $M L_{\text {total }}$ is calculated as shown below, where $Q \in\{1,2,3,4\}$ is the total number of rated product lifecycle phase.

$M L_{\text {total }}=\left(\frac{1}{Q+1}\right)\left(M L_{c l}+\sum_{q=1}^{Q} M L_{p l p q}\right)$.

According to the structure of the InAsPro-maturity model, $M L_{s c a}$ has to be always determined. Depending on the product lifecycle phase the user is looking at, only those phases are considered within the calculation. An application example is described in Sect. 4. Adding additional weighting factorsto the calculation is possible, but it is not recommended, as this might shift the results and will therefore hide the less digitalized areas. All product lifecycle phases should be treated equally, and the prioritization of the digitalization process depends on the company's internal decisions.

\subsection{Model architecture and its components}

The InAsPro maturity model is structured according to different levels of consideration: the Corporate Level and levels corresponding to the product lifecycle phases (Development, Production, Assembly, and Aftersales) (Fig. 5). The Corporate Level focuses on companywide aspects such as digital strategy, business models, and IT security, to gain an overall impression of the digitalization level of the company.

For each level of consideration, the model analyzes the Technology, Organization, and Social dimensions. On the Corporate Level, the Strategy dimension is added as a fourth dimension. Note that strategy can only be investigated on the Corporate Level because strategy (according to its definition) refers to decisions on how the company will create or maintain competitive advantages [66]. This decision can only be made at a Corporate Level. Actions performed within individual product lifecycle phases can implicitly support the strategy $[71,72]$ but cannot define a unique strategy [73].

Each dimension is described by criteria such as "IT-System Design" or "Customer Service" within the Technology dimension and "Corporate Culture" or "Leadership" within the Social dimension. Furthermore, the criteria depend on the level of consideration. Within the Organization and Social dimensions, all criteria for the Corporate Level are

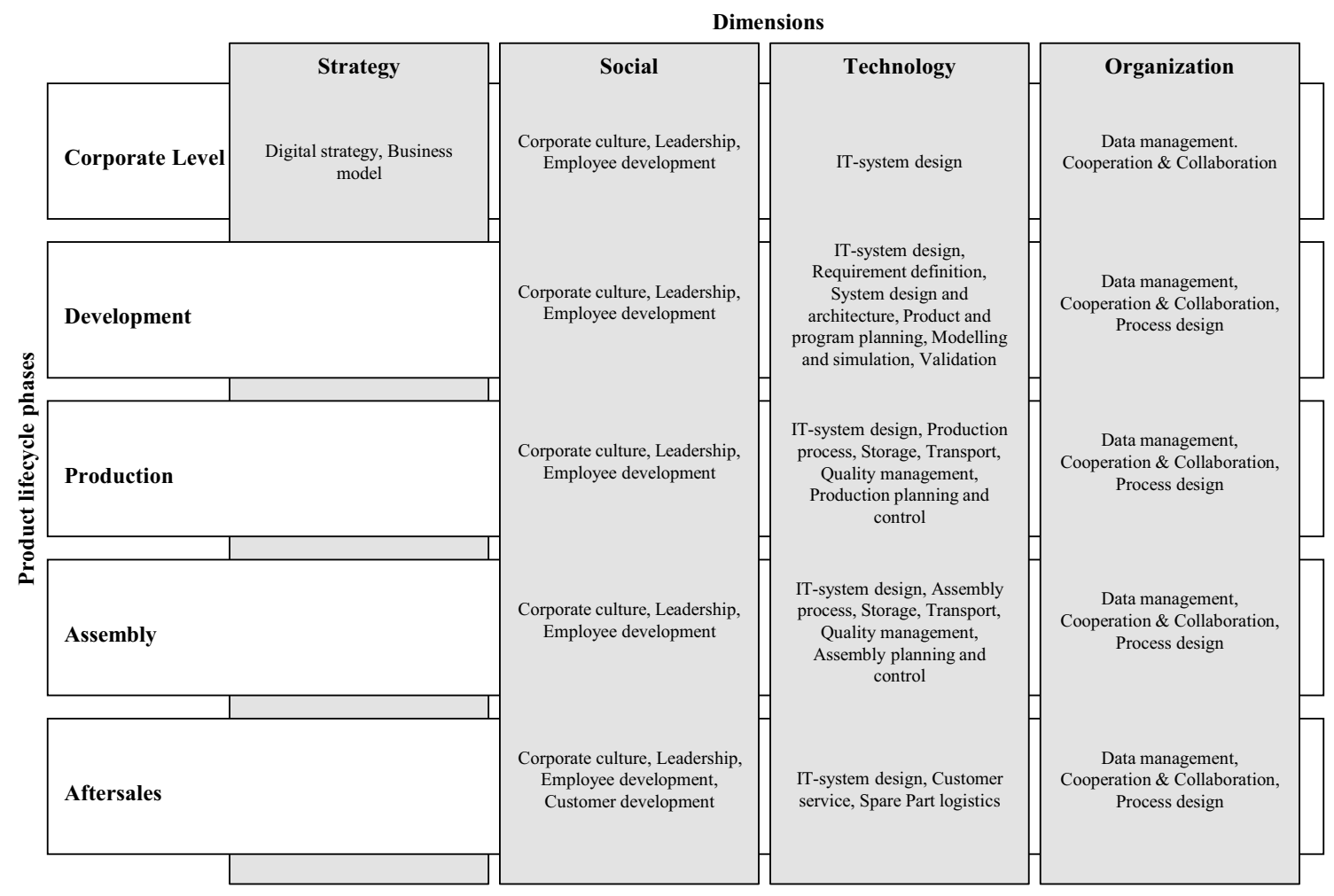

Fig. 5 Structure of InAsPro maturity model, with its product lifecycle phases, dimensions, and criteria [1] 
the same as those for the product lifecycle phases. Only within the Technology dimension do the criteria vary. This is because of the specific use of digital technologies with certain purposes in a given product lifecycle phase. The criteria associated with both the dimensions and the levels of consideration are shown in Fig. 5.

Indicators describe the abovementioned criteria. For example, an indicator for the Transport criterion within the Technology dimension is identification of components in a manufacturing process (Table 3). The indicators are developed iteratively within the InAsPro project and are formulated as questions. Each indicator contains four stages representing the digitalization progress of the associated criterion. They are described textually (see also supplementary material). The first stage starts with an indicator having no or low digitalization whereas the fourth stage describes a fully digitalized indicator (Fig. 6).

Within the Organization and Social dimensions, the majority of the criteria have the same name, but the indicators vary in accordance with their associated product lifecycle phase. Therefore, the indicators must be evaluated considering their context within their individual product lifecycle phases. As an example, the Leadership criterion contains the "Communication of digitalization projects" indicator, which may vary between the product lifecycle phases in response to different executives with different management styles. Furthermore, the presence of the same criteria across the product lifecycle phases and the Corporate Level allows easier comparison of the degree to which a given criterion is digitized. A selection of criteria, indicators, and stages of the InAsPro maturity model are presented in Table 3. An example of the Corporate level (IT-System Design) points out the detailed description of the maturity stage definitions and is given in Table 4. A detailed description of the full set including the stage definitions and their detailed descriptions, are presented in the attached "InAsPro maturity model guide" as well as in the software demonstrator [74].

As the InAsPro maturity model is implemented within a software demonstrator, it begins with introductory questions consisting of general questions, e.g., questions regarding the company branch that is presently active or the number of employees employed by the company (Fig. 7). The introductory questions enable categorization of the data sets regarding different sectors, countries and regions, company size, etc. Consequently, setting a benchmark between these categories is possible.

\section{Application of InAsPro maturity model}

The InAsPro maturity model includes a comprehensive examination of the degree of digitization. Based on the results, individual measures are derived in the subsequent step with the help of the digitization strategies which were developed in the InAsPro project. This enables an individual digital transformation of manufacturing companies [75]. The application of the InAsPro maturity model is supported by the software demonstrator, which guides users step by step through the maturity model. Prior knowledge for the application of the maturity model is required on the content level, so it is recommended that the evaluation of the indicators is carried out by experts from the specific business units [76].

\subsection{Application strategy}

In the initial application stages of the InAsPro maturity model, the user chooses the product lifecycle phases they wish to assess. The user can choose one or all four product lifecycle phases depending on the individual objectives of the maturity assessment. Answers to the Introductory Questions and those concerning the Corporate Level are obligatory because of the structure of the maturity model (Sect. 3.5).

To perform the assessment, it is recommended that different persons evaluate the indicators on the basis of their stages in the maturity model. For example, the Corporate Level evaluation should be performed by a group of employees familiar with the strategic orientation of the company, who can make accurate statements about the indicators at this level. For assessment of the product lifecycle phases, it is best to include the relevant divisional managers and experts in the evaluation process, especially if more than one phase is assessed. This provides a more objective view of the digitalization statuses of the considered product lifecycle phases. To summarize, assessment of the company maturity level as well as the product lifecycle phases is ideally performed by a team composed of experts in individual areas.

\subsection{Application example and displayed results}

As an example, the developed maturity model was applied to a small and medium-sized enterprise (SME) within the mechanical engineering sector to determine its digitalization maturity level in the Development and Production product lifecycle phases. The company develops and produces its own products with high variety due to customer-specific requirements and delivers german and international markets. After applying the maturity model to the chosen product lifecycle phases, the assessment results were displayed within tables and radar charts. The results are shown separately according to the obligatory Corporate Level and the chosen product lifecycle phases. First, the result of the company's digitalization maturity level is shown (Fig. 8). The SME has a total digitalization level of 2.0, which means it is still a Beginner in the context of digitalization. The description of this maturity level is given in Fig. 4. 


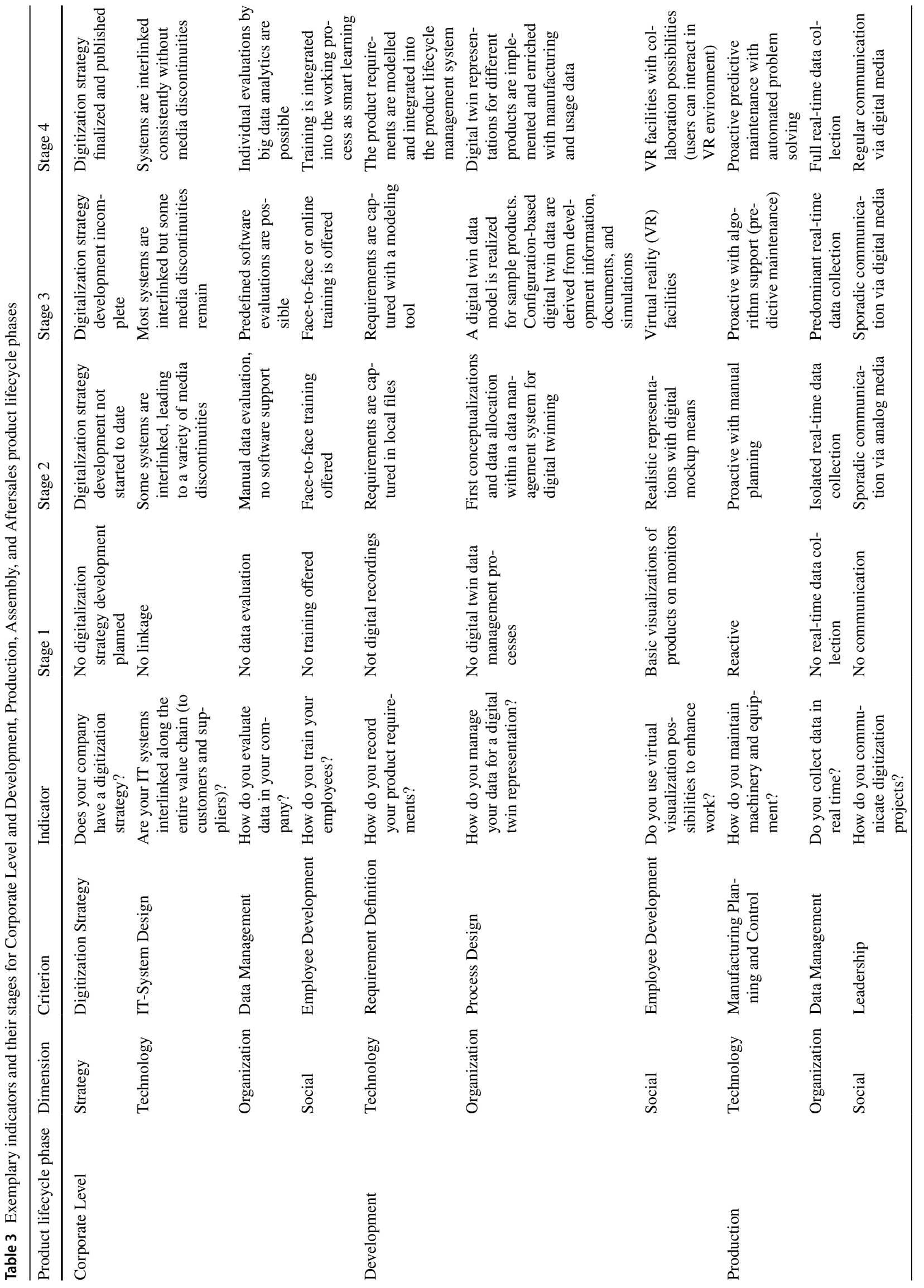




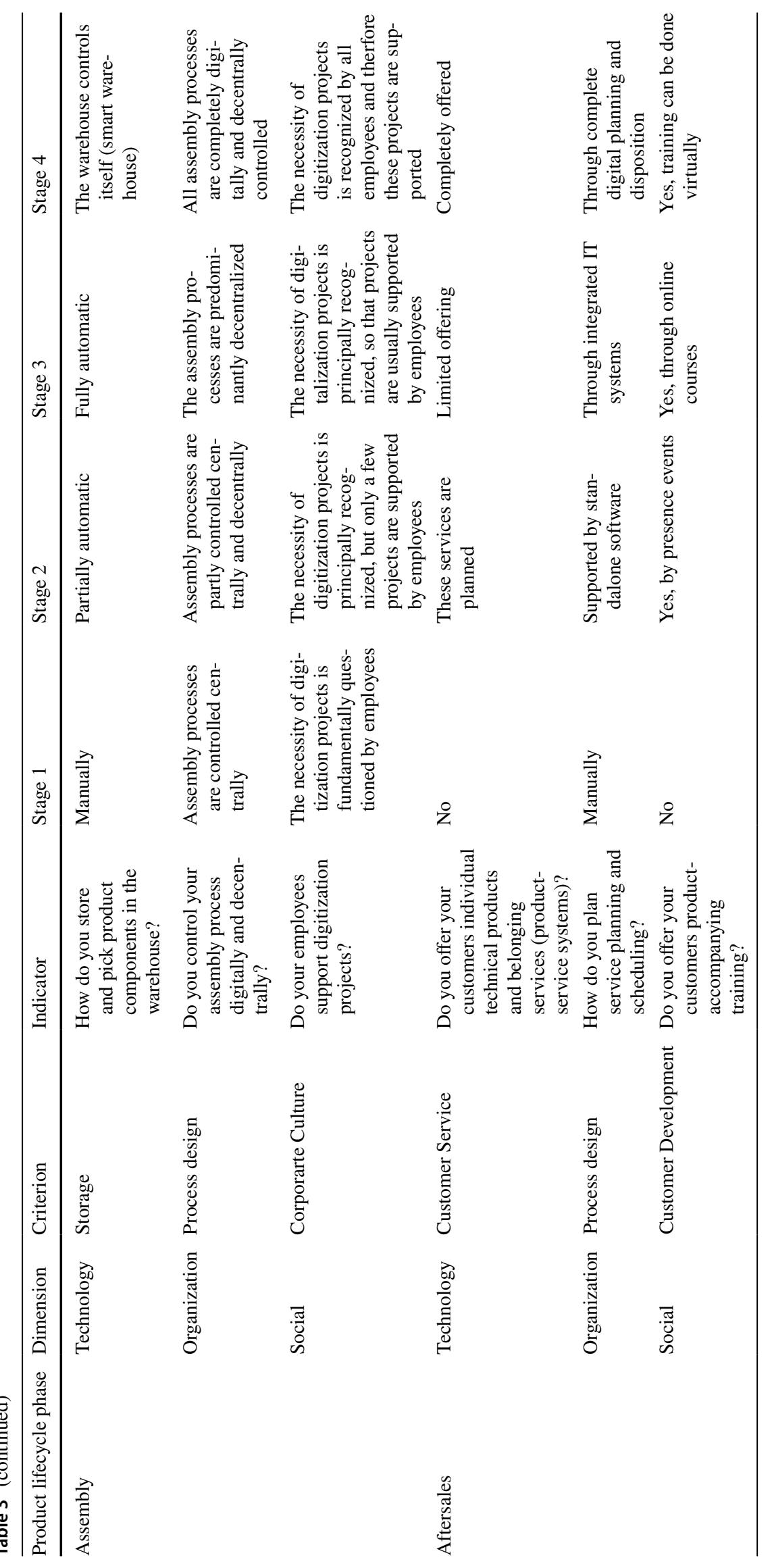




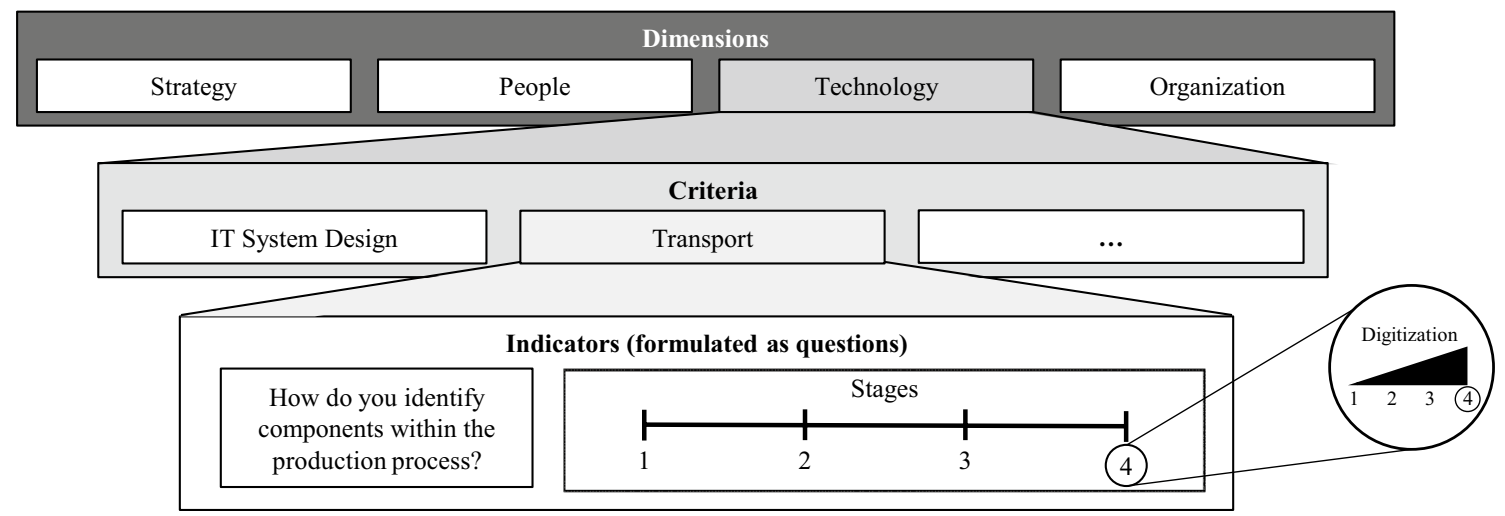

Fig. 6 Description of dimensions, criteria, indicators, and stages [1]

For a more detailed insight, the total result was decomposed into the considered dimensions, i.e., Technology, Organization, Social, and Strategy (Fig. 9). The SME ranked on the Beginner level for all dimensions, but performed strongest in the Social dimension. For each dimension, the calculated results were presented in a radar chart containing the dimension's criteria, e.g., IT-System Design as well as Requirement Definition, to provide more detailed identification of the strengths and weaknesses. As an example, the SME digitalization was found to be Advanced regarding the System Design \& Architecture and Modeling \& Simulation criteria, but the company was rated as an Explorer in the Quality Management and Production Planning \& Control criteria. Therefore, there is potential for improvement in these areas. As only Development and Production were assessed for the SME, no values were given for the Customer Service and Spare Parts Logistics criteria.

In addition, the assessed digitalization maturity level was presented in terms of the processed individual product lifecycle phases, i.e., Development, Production, Assembly, and Aftersales, as well as the Corporate Level (Fig. 10). Therefore, the SME received individual digitalization maturity values for Development and Production. The assessments for all product lifecycle phases could also be examined in more detail by displaying their specific criteria. In this paper, the result for Production is used as an example (Fig. 10(2)).

The displayed graphs show well-digitized areas (values above 2.5) and areas with potential for improvement (values below 2.5). Therefore, the SME decisionmakers are provided with a basis on how to proceed. For instance, the already well-digitized areas (the pioneering strategy) of the SME can be taken as his strength the company could follow the pioneering strategies and advance his capabilities in these fields. Moreover, the less digitized areas (successor strategy) can be improved indicating a successor strategy to maintain competitiveness. Consequently, the maturity assessment results provided by the InAsPro maturity model serve as a starting point for the development of a digitalization strategy, or for questioning and adjusting an already existing digitalization strategy within a company.

\section{Results and discussion}

The successful digitalization of a manufacturing company requires knowledge of its status quo regarding digitalization of established technical systems, organizational structures, and processes, as well as social factors. Based on this knowledge, the company can set an individual digitalization goal in all the considered areas.

The InAsPro maturity model presented in this study enables manufacturing companies to gain an initial insight into their current digitalization level by not only considering the whole company, but also differentiating between the Corporate Level of a company and the Development, Production, Assembly, and Aftersales product lifecycle phases. The maturity model also equally contemplates the Technology, Organization, and Social dimensions. Additionally, a Strategy dimension is incorporated into the Corporate Level (Sect. 3.5) of the model. The total assessment result given by the proposed maturity model allocates one of four maturity levels to the company, which contain a detailed description of the individual digitalization degree (Sect. 3.4). Furthermore, the calculated results are displayed in several graphs, showing the total result for the company as well as detailed results for all product lifecycle phases and dimensions (Sect. 4.2). 


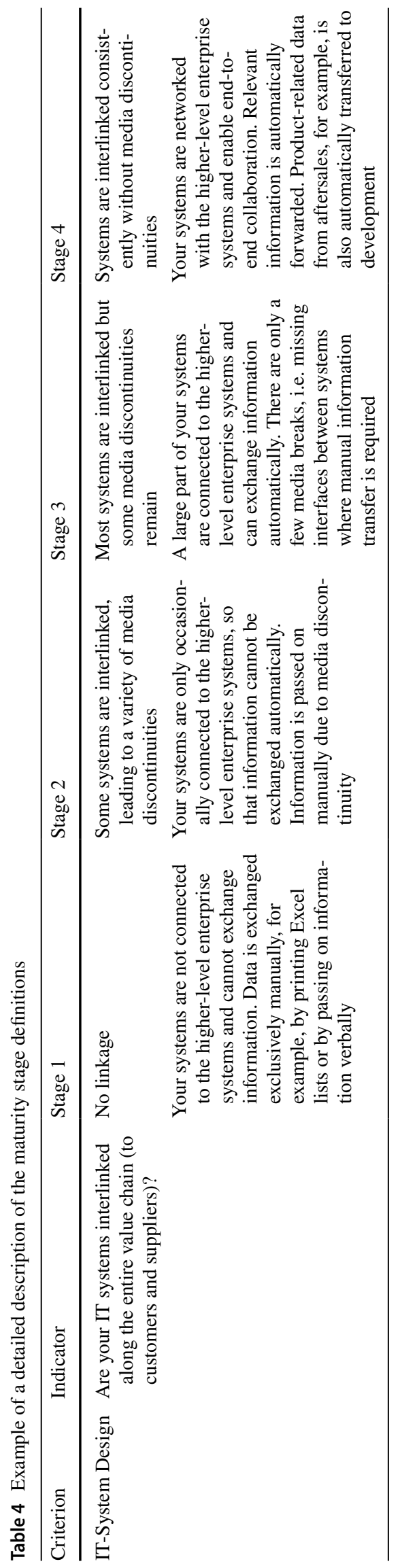

\subsection{Conclusion}

Compared to existing digitalization maturity models, the developed InAsPro maturity model implements a holistic approach by considering multiple aspects of a company. That is, consideration of the Corporate Level as well as the Development, Production, Assembly, and Aftersales product lifecycle phases provides an integrated view of digitalization within the company. In particular, the crucial differentiation between the Production and Assembly heterogenous phases separates the proposed model from earlier approaches. Furthermore, the maturity model incorporates the Technology, Organization, and Social dimensions and adds Corporate Strategy to the overview. The maturity model has been developed so that work systems of different sizes can be evaluated. Thus, for example, a company can assess a workstation and, simultaneously, an entire department, in terms of digitalization.

Additionally, the maturity model facilitates comparisons between the product lifecycle phases; the acquired results can be used as a benchmark between manufacturing companies and across sectors. This aspect is ensured because the maturity model is intended to be implemented within a software demonstrator; thus, manufacturing companies can perform the assessment online. Therefore, anonymous results from different users can be compared objectively. Furthermore, differences in perception between the top management and divisional managers can be revealed, if repeatedly applied questions are answered differently on the Corporate Level and on the level of the product lifecycle phases (Sects. 3.5 and 4.1).

As technology evolves rapidly, different technologies are not explicitly considered in the maturity model and are not attributed to individual maturity levels. Furthermore, the maturity model reflects the current state and the target state is not presented. The target state is defined in the next step of the InAsPro research project using the developed concept of digitalization strategies [77]. Based on the digitalization strategies and the technology map previously reported by the authors [21], recommendations for specific application scenarios can be derived. By combining the InAsPro maturity model with the already developed technology map and digitalization strategies, a holistic modular transformation concept for work-system digitalization is developed. The concept supports companies in digitizing their work systems step by step and accompanies the implementation [2]. Furthermore, the concept was transferred into a software demonstrator, making it available for the use by the general public [74]. 


\section{CREATE A NEW PROJECT}

Project name

In which sector are you presently active?

Automotive industry

IT industry

Engineering

Metal and mechanical products sector

Electrical and electronics industry

Other

In which country is your company registered?
Please estimate the number of company employees.

up to 19 employees

20 to 99 employees

100 to 249 employees

250 to 499 employees

500 or more employees

Do you work nationally or internationally?

- national

international

What is your position in the company?

What is the postcode of your region? Please enter the first two digits of your postal code area

Fig. 7 InAsPro maturity model: introductory questions [74]

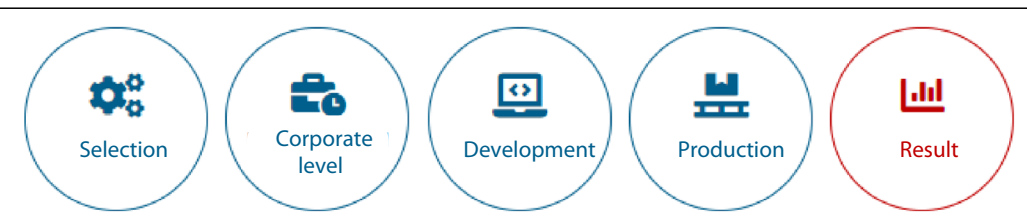

TOTAL RESULT

Company digitalization level:: 2

\begin{tabular}{|c|c|c|c|}
\hline Explorer & Beginner & Advanced & Expert \\
\hline $1-1.4$ & $1.5-2.4$ & $2.5-3.4$ & $3.5-4$ \\
\hline
\end{tabular}

Fig. 8 Total company assessment result 


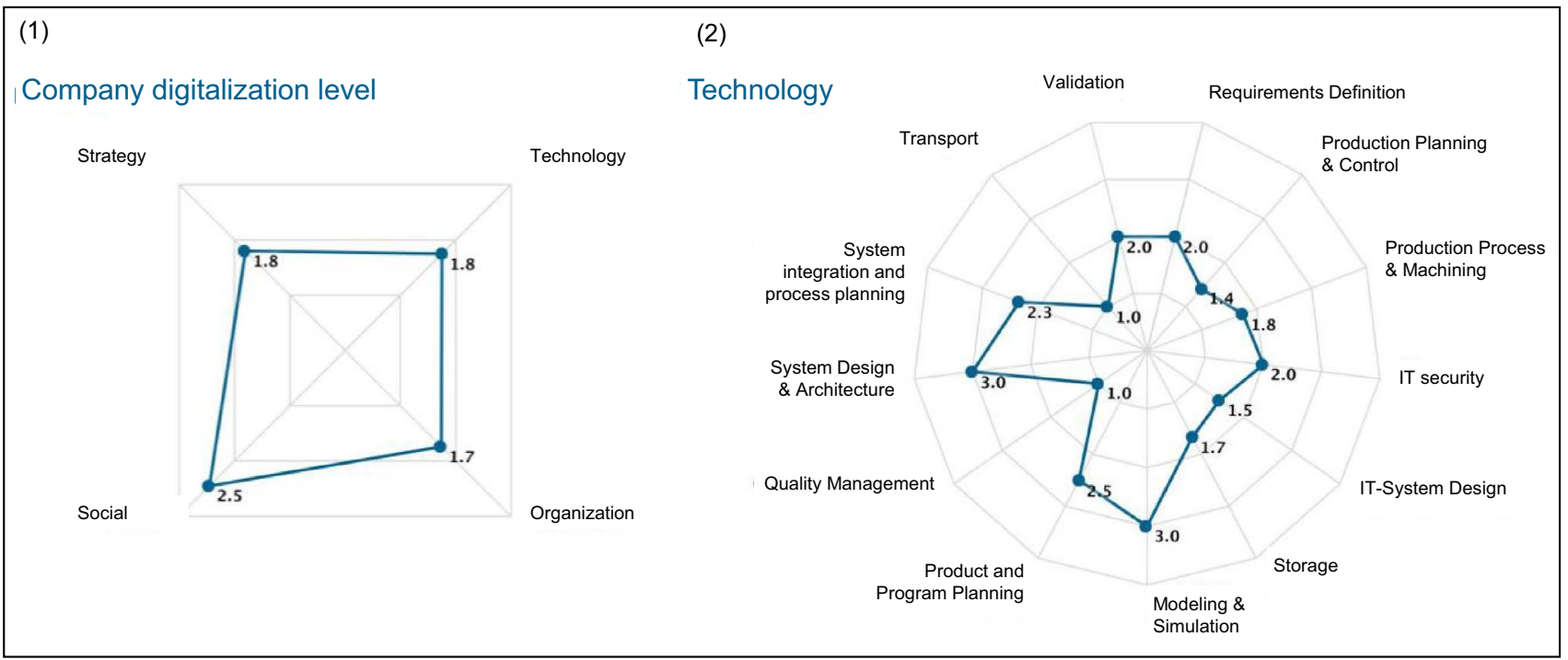

Fig. 9 (1) Overview of company digitalization levels for Technology, Organization, Social, and Strategy criteria on Corporate Level and (2) for Technology criterion only

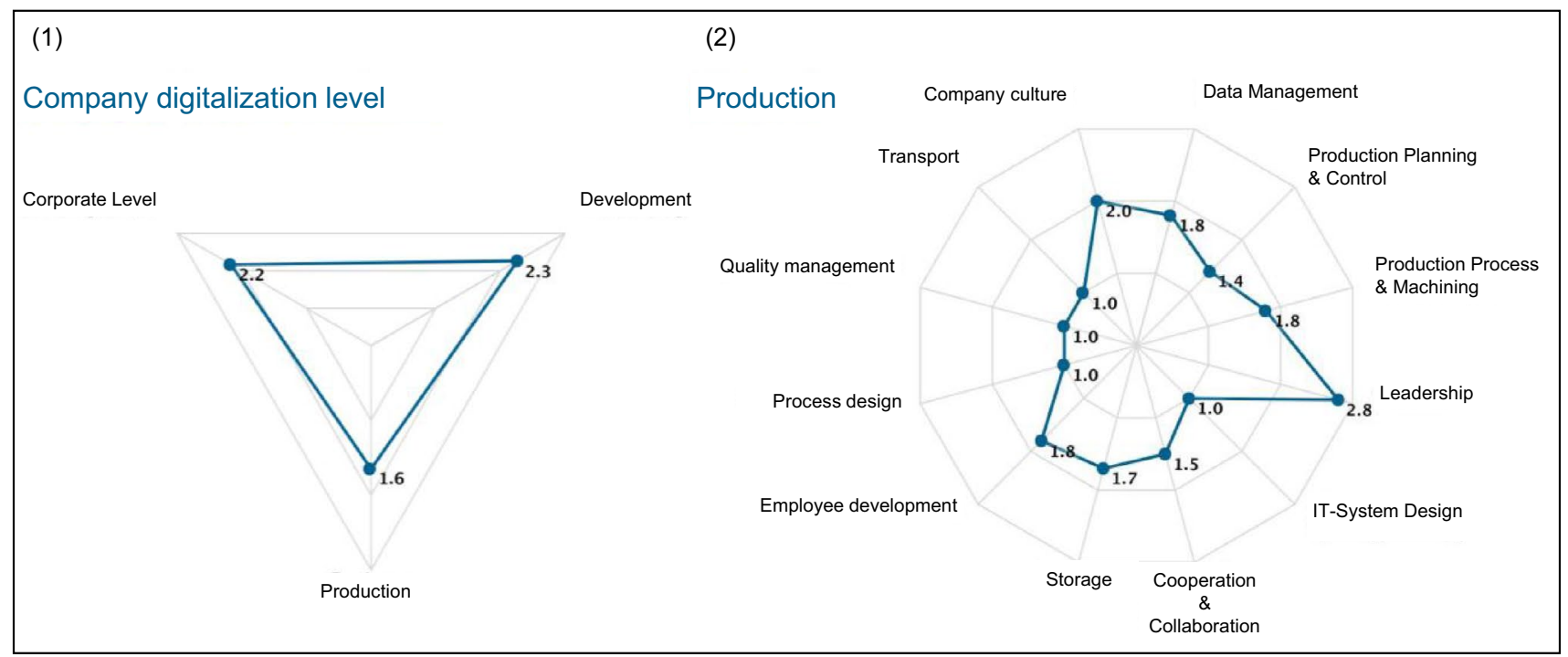

Fig. 10 Overview of company digitalization levels for (1) all product lifecycle phases and (2) Production product lifecycle phase only

Supplementary Information The online version contains supplementary material available at https://doi.org/10.1007/s11740-021-01044-4.

Acknowledgements This research and development project was funded by the German Federal Ministry of Education and Research (BMBF) and by the European Social Fund (ESF) under the 'Zukunft der Arbeit' program (InAsPro; grant number 02L15A244).
Funding Open Access funding enabled and organized by Projekt DEAL.

\section{Declarations}

Funding This research and development project was funded by the German Federal Ministry of Education and Research (BMBF) and by 
the European Social Fund (ESF) under the 'Zukunft der Arbeit' program (InAsPro; grant number 02L15A244).

Conflict of interest The authors declare that they have no conflict of interest.

Availability of data and material (data transparency) InAsPro maturity model guide.

Code availability Not applicable.

Author contributions Conceptualization: Carina Siedler, Stephanie Dupont, Mona Tafvizi Zavareh, Tobias Ehemann, Frank Zeihsel; Methodology: Carina Siedler, Stephanie Dupont, Mona Tafvizi Zavareh, Tobias Ehemann, Frank Zeihsel; Writing - original draft preparation: Carina Siedler, Stephanie Dupont, Mona Tafvizi Zavareh, Tobias Ehemann, Frank Zeihsel, Chantal Sinnwell; Writing - review and editing: Carina Siedler, Jens C. Göbel, Klaus J. Zink, Jan C. Aurich; Supervision: Jens C. Göbel, Klaus J. Zink, Jan C. Aurich.

Open Access This article is licensed under a Creative Commons Attribution 4.0 International License, which permits use, sharing, adaptation, distribution and reproduction in any medium or format, as long as you give appropriate credit to the original author(s) and the source, provide a link to the Creative Commons licence, and indicate if changes were made. The images or other third party material in this article are included in the article's Creative Commons licence, unless indicated otherwise in a credit line to the material. If material is not included in the article's Creative Commons licence and your intended use is not permitted by statutory regulation or exceeds the permitted use, you will need to obtain permission directly from the copyright holder. To view a copy of this licence, visit http://creativecommons.org/licenses/by/4.0/.

\section{References}

1. Siedler C, Dupont S, Tafvizi Zavareh M et al (2020) Reifegradmodell zur Bestimmung des Digitalisieurngsgrads. In: Aurich JC, Pier M, Siedler C, Sinnwell C (eds) Bedarfsgerechte Digitalisierung von Produktionsunternehmen. Synnovating, Kaiserslautern, pp 21-36

2. Aurich JC, Pier M, Siedler C, Sinnwell C (ed.) (2020) Bedarfsgerechte Digitalisierung von Produktionsunternehmen: Ein modulares Transformationskonzept als praxisorientierter Ansatz. Synnovating

3. Monostori L, Kádár B, Bauernhansl T et al (2016) Cyber-physical systems in manufacturing. CIRP Ann Manuf Technol 65:621-641. https://doi.org/10.1016/j.cirp.2016.06.005

4. Qin J, Liu Y, Grosvenor R (2016) A categorical framework of manufacturing for industry 4.0 and beyond. Procedia CIRP 52:173-178. https://doi.org/10.1016/j.procir.2016.08.005

5. Jäger J, Schöllhammer O, Lickefett $M$ et al (2016) Advanced complexity management strategic recommendations of handling the "Industrie 4.0" complexity for SMALL AND MEDIUM ENTERPRISES. Procedia CIRP 57:116-121. https://doi.org/10.1016/j. procir.2016.11.021

6. Telukdarie A, Buhulaiga E, Bag S et al (2018) Industry 4.0 implementation for multinationals. Process Saf Environ Prot 118:316329. https://doi.org/10.1016/j.psep.2018.06.030

7. Krugh M, Mears L (2018) A complementary cyber-human systems framework for industry 4.0 cyber-physical systems. Manuf Lett 15:89-92. https://doi.org/10.1016/j.mfglet.2018.01.003
8. Benešová A, Tupa J (2017) Requirements for education and qualification of people in industry 4.0. Procedia Manuf 11:2195-2202. https://doi.org/10.1016/j.promfg.2017.07.366

9. de Carolis A, Macchi M, Kulvatunyou B et al (2017) Maturity Models and Tools for Enabling Smart Manufacturing Systems: Comparison and Reflections for Future Developments. In: Ríos J, Bernard A, Bouras A, Foufou S (eds) Product lifecycle management and the industry of the future. Springer, Cham, pp 23-35

10. Bley K, Schön H (2019) A Role-Based Maturity Model for Digital Relevance. In: Pappas IO, Mikalef P, Dwivedi YK, Jaccheri L, Krogstie J, Mäntymäki M (eds) Digital Transformation for a Sustainable Society in the 21st Century. Springer International Publishing, Cham, pp 738-744

11. Coreynen W, Matthyssens P, van Bockhaven W (2017) Boosting servitization through digitization: Pathways and dynamic resource configurations for manufacturers. Ind Market Manag 60(2017):42-53

12. Busby ES (1975) Principles of digital television simplified. J SMPTE 84:542-545. https://doi.org/10.5594/J13338

13. Hirsch-Kreinsen H (2016) Digitization of industrial work: development paths and prospects. J Labour Market Res 49:1-14. https ://doi.org/10.1007/s12651-016-0200-6

14. Vial G (2019) Understanding digital transformation: a review and a research agenda. J Strateg Inf Syst. https://doi.org/10.1016/j. jsis.2019.01.003

15. Posada J, Toro C, Barandiaran I et al (2015) Visual computing as a key enabling technology for Industrie 4.0 and Industrial Internet. IEEE Comput Graphics Appl 35:26-40. https://doi.org/10.1109/ MCG.2015.45

16. Abramovici M, Göbel JC, Savarino P (2017) Reconfiguration of smart products during their use phase based on virtual product twins. CIRP Ann Manuf Technol 66:165-168. https://doi. org/10.1016/j.cirp.2017.04.042

17. Bauer W, Schlund S, Hämmerle $M$ et al (2014) Industrie 4.0 Eine Revolution der Arbeitsgestaltung: Wie Automatisierung und Digitalisierung unsere Produktion verändern werden

18. Kagermann H, Wahlster W, Helbig J (2013) Recommendations for implementing the strategic initiative INDUSTRIE 4.0: Securing the future of German manufacturing industry

19. Carolis A de, Macchi M, Negri E et al (2017) A Maturity Model for Assessing the Digital Readiness of Manufacturing Companies. In: Lödding H, Riedel R, Thoben K-D, Cieminski G von, Kiritsis D (eds) Advances in Production Management Systems. The Path to Intelligent, Collaborative and Sustainable Manufacturing. Springer International Publishing, Cham, pp 13-20

20. Broy M (2013) Engineering Cyber-Physical Systems: Challenges and Foundations. In: Aiguier M, Caseau Y, Krob D, Rauzy A (eds) Complex Systems Design \& Management. Springer, Berlin Heidelberg, Berlin, Heidelberg, pp 1-13

21. Siedler C, Sadaune S, Zavareh MT et al (2019) Categorizing and selecting digitization technologies for their implementation within different product lifecycle phases. Procedia CIRP 79:274-279. https://doi.org/10.1016/j.procir.2019.02.066

22. Nee A, Ong SK, Chryssolouris G et al (2012) Augmented reality applications in design and manufacturing. CIRP Ann Manuf Technol 61:657-679. https://doi.org/10.1016/j.cirp.2012.05.010

23. Louw L, Walker M (2018) Design and implementation of a low cost RFID track and trace system in a learning factory. Procedia Manuf 23:255-260. https://doi.org/10.1016/j.promfg.2018.04.026

24. Porter ME, Heppelmann JE (2015) How smart, connected products are transforming companies. Harvard Bus Rev (HBR) 93:96-114

25. Hayes RH, Wheelwright SC (2003) Link manufacturing process and product life cycles. In: Lewis MA, Slack N (eds) Operations management: critical perspectives on business and management, 3. Auflage. Routledge, London u. a 
26. Kölscheid W (1999) Methodik zur lebenszyklusorientierten Produktgestaltung. Dissertation, Rheinisch-Westfälische Technische Hochschule Aachen

27. TUK - Technische Universität Kaiserslautern (2017) Joint research project InAsPro. https://www.inaspro.de/. Accessed 6 November 2018

28. Abramovici M (2014) Smart Products. In: Arrazola Arriola PJ (ed) Modelling in Cutting. Springer, Berlin Heidelberg, Berlin, Heidelberg, pp 1-5

29. Warnecke H-J (1995) Der Produktionsbetrieb 2. Springer, Berlin, Heidelberg

30. Lotter B, Wiendahl H-P (2006) Montage in der industriellen Produktion. Springer, Berlin, Heidelberg

31. Wiendahl H-P (2014) Betriebsorganisation für Ingenieure. HanserMünchen

32. Wang L, Gao RX (2006) Condition Monitoring and Control for Intelligent Manufacturing. Springer-VerlagLondon

33. Saccani N, Johansson P, Perona M (2007) Configuring the aftersales service supply chain: a multiple case study. Int J Prod Econ 110:52-69. https://doi.org/10.1016/j.ijpe.2007.02.009

34. Hill AV, Collier DA, Froehle CM et al (2002) Research opportunities in service process design. J Oper Manag 20:189-202. https:// doi.org/10.1016/S0272-6963(01)00092-4

35. Aurich JC, Mannweiler C, Schweitzer E (2010) How to design and offer services successfully. CIRP J Manuf Sci Technol 2:136-143. https://doi.org/10.1016/j.cirpj.2010.03.002

36. Mont O (2002) Clarifying the concept of product-service system. J Clean Prod 10:237-245. https://doi.org/10.1016/S0959 -6526(01)00039-7

37. Meier H, Roy R, Seliger G (2010) Industrial product-service systems-IPS 2. CIRP Ann Manuf Technol 59:607-627. https://doi. org/10.1016/j.cirp.2010.05.004

38. Kölsch P, Herder CF, Zimmermann V et al (2017) A novel concept for the development of availability-oriented business models. Procedia CIRP 64:340-344. https://doi.org/10.1016/j.proci r.2017.03.063

39. Hersey P, Blanchard KH (1977) Management of Organizational Behavior: Utilizing Human Resources. Prentice-Hall, New Jersy

40. Mettler T (2010) Vorschlag zur Wiederauffindung und Wiederverwendung von Reifegradmodellen

41. Fraser P, Moultrie J, Gregory M (2002) The Use of Maturity Models/Grids as a Tool in Assessing Product Development Capability. In: Proceedings - IEEE Engineering Management Society (ed) Managing technology for the new economy. IEEE Operations Center, Piscataway, NJ, pp 244-249

42. Hellge V, Schröder D, Zink KJ (2018) Der Readiness Check "Digitalisierung" als Instrument im digitalen Transformationsprozess. In: Lingnau V, Müller-Seitz G, Roth S (eds) Management der digitalen Transformation. Verlag Franz Vahlen, München, pp 171-186

43. Schuh G, Anderl R, Gausemeier J et al (2017) Industrie 4.0 Maturity Index: Managing the Digital Transformation of Companies

44. Lichtblau K, Stich V, Bertenrath R et al (2015) Industrie 4.0-Readiness

45. Berghaus S, Back A, Kaltenrieder B (2017) Digital Maturity \& Transformation Report 2017

46. Schumacher A, Erol S, Sihn W (2016) A maturity model for assessing industry 4.0 readiness and maturity of manufacturing enterprises. Procedia CIRP 52:161-166. https://doi.org/10.1016/j.proci r.2016.07.040

47. Leineweber S, Wienbruch T, Lins D et al (2018) Concept for an evolutionary maturity based Industrie 4.0 migration model. Procedia CIRP 72:404-409. https://doi.org/10.1016/j.procir.2018.03.155

48. Lanza G, Nyhuis P, Ansari SM et al (2016) Befähigungsund Einführungsstrategien für Industrie 4.0. ZWF Zeitschrift für wirtschaftlichen Fabrikbetrieb 111:76-79. https://doi. org/10.3139/104.111462
49. Lanza, G., Nyhuis, P., Editors (2018) Industrie 4.0 für die Praxis: Befähigungs- und Einführungsstrategien. TEWISS Verlag TEWISSTechnik und Wissen GmbH

50. Pokorni B, Schlund S, Findeisen S et al (2017) Produktionsassessment 4.0. ZWF Zeitschrift für wirtschaftlichen Fabrikbetrieb 112:20-24. https://doi.org/10.3139/104.111662

51. Anderl R, Fleischer J (2015) Guideline Industrie 4.0. VDMA-Verl. Frankfurt am Main.

52. Jung K, Kulvatunyou B, Choi S et al (2017) An overview of a smart manufacturing system readiness assessment. IFIP Adv Inf Commun Technol 488:705-712. https://doi.org/10.1007/978-3-319-51133 $-7 \_83$

53. Li Q, Brundage M, Kulvatunyou B et al (2017) Improvement Strategies for Manufacturers Using the MESA MOM Capability Maturity Model. In: Lödding H, Riedel R, Thoben K-D, Cieminski G von, Kiritsis D (eds) Advances in Production Management Systems. The Path to Intelligent, Collaborative and Sustainable Manufacturing. Springer International Publishing, Cham, pp 21-29.

54. Jodlbauer H, Schagerl M (2016) Reifegradmodell Industrie 4.0: Ein Vorgehensmodell zur Identifikation von Industrie 4.0 Potentialen. In: Mayr HC, Pinzger M (eds) Informatik 2016, Bonn, pp 1473-1487

55. Leyh C, Schäffer T, Bley K et al (2016) SIMMI 4.0 - A Maturity Model for Classifying the Enterprise-wide IT and Software Landscape Focusing on Industry 4.0. In: Federated Conference on Computer Science and Information Systems (ed) Annals of Computer Science and Information Systems. IEEE, pp 1297-1302

56. Leyh C, Schäffer T, Forstenhäusler S (2016) SIMMI 4.0: Vorschlag eines Reifegradmodells zur Klassifikation der unternehmensweiten Anwendungssystemlandschaft mit Fokus Industrie 4.0. MKWI 2016 - IT- und Software-Produktmanagement in IoT-basierten Infrastrukturen:981-992

57. Gracel J, Lebkowski P (2019) The concept of industry 4.0 related manufacturing technology maturity model (Manutech Maturity Model, MTMM). Decis Making Manuf Serv 12:17-31. https://doi. org/10.7494/dmms.2018.12.1-2.17

58. Jæger B, Halse LL (2017) The IoT Technological Maturity Assessment Scorecard: A Case Study of Norwegian Manufacturing Companies. In: Lödding H, Riedel R, Thoben K-D, Cieminski G von, Kiritsis D (eds) Advances in Production Management Systems. The Path to Intelligent, Collaborative and Sustainable Manufacturing. Springer International Publishing, Cham, pp 143-150

59. Klötzer C, Pflaum A (2017) Toward the Development of a Maturity Model for Digitalization within the Manufacturing Industry's Supply Chain. Proceedings of the 50th Hawaii International Conference on System Sciences 2017.:4210-4219

60. Gökalp E, Şener U, Eren PE (2017) Development of an Assessment Model for Industry 4.0: Industry 4.0-MM. In: Mas A, Mesquida A, O'Connor RV, Rout T, Dorling A (eds) Software Process Improvement and Capability Determination. Springer International Publishing, Cham, pp 128-142

61. Paschou T, Rapaccini M, Peters C et al (2020) Developing a Maturity Model for Digital Servitization in Manufacturing Firms. In: Anisic Z, Lalic B, Gracanin D (eds) Proceedings on 25th International Joint Conference on Industrial Engineering and Operations Management - IJCIEOM. Springer International Publishing, Cham, pp 413-425

62. Schumacher A, Nemeth T, Sihn W (2019) Roadmapping towards industrial digitalization based on an Industry 4.0 maturity model for manufacturing enterprises. Procedia CIRP 79:409-414. https://doi. org/10.1016/j.procir.2019.02.110

63. Mittal S, Khan MA, Romero D et al (2018) A critical review of smart manufacturing \& Industry 4.0 maturity models: implications for small and medium-sized enterprises (SMEs). J Manuf Syst 49:194-214. https://doi.org/10.1016/j.jmsy.2018.10.005

64. Tafvizi Zavareh M, Sadaune S, Siedler C et alA Study on the sociotechnical Potentials of industrial Product Development Technologies 
for future digitized integrated Work Systems Proceedings of Norddesign 2018, Linköpig, Sweden

65. Ulich E (2011) Arbeitspsychologie. vdf Hochschulverlag AG an der ETH Zürich; Schöffer-Poeschel VerlagZürich, Stuttgart

66. Schallmo D, Williams CA, Lohse J (2018) Clarifying Digital Strategy: Detailed Literature Review of Existing Approaches. Proceedings of The XXIX ISPIM Innovation Conference - Innovation, The Name of the Game:1-21

67. Bruin T de, Freeze R, Kaulkarni U et al (2005) Understanding the Main Phases of Developing a Maturity Assessment Model. Proceedings of Australasian Conference on Information Systems (ACIS)

68. Becker J, Knackstedt R, Pöppelbuß J (2009) Entwicklung von Reifegradmodellen für das IT-Management. Wirtschaftsinformatik 51:249-260. https://doi.org/10.1007/s11576-009-0167-9

69. Akkasoglu G (2013) Methodik zur Konzeption und Applikation anwendungsspezifischer Reifegradmodelle unter Berücksichtigung der Informationsunsicherheit. Dissertation, Friedrich-AlexanderUniversität Erlangen-Nürnberg

70. Kübel M (2013) Corporate M\&A. Springer Fachmedien WiesbadenWiesbaden

71. Terziyan V, Gryshko S, Golovianko M (2018) Patented intelligence: cloning human decision models for Industry 4.0. J Manuf Syst 48:204-217. https://doi.org/10.1016/j.jmsy.2018.04.019
72. Wernz C, Deshmukh A (2007) Decision strategies and design of agent interactions in hierarchical manufacturing systems. J Manuf Syst 26:135-143. https://doi.org/10.1016/j.jmsy.2007.10.003

73. Ross JW, Sebastian IM, Beath CM (2017) How to develop a great digital strategy. MIT Sloan Manag Rev 58:6-9

74. Zeihsel FSoftware Demonstrator "Digitalization Planner". https:// www.inaspro.de/Demonstrator/index.php. Accessed 13th July 2020

75. VDI/VDE-Gesellschaft Mess- und Automatisierungstechnik (2021) VDI/VDE 4000-1: Systematic transformation and evaluation of production systems - Fundamentals (Draft). Düsseldorf

76. VDI/VDE-Gesellschaft Mess- und Automatisierungstechnik (2021) VDI/VDE 4000-2: Systematic transformation and evaluation of pro-duction systems - Selection of the appropriate model (Draft). Düsseldorf

77. Dupont S, Tafvizi Zavareh M, Zeihsel F et al (2020) Entwicklung von Digitalisierungsstrategien. In: Aurich JC, Pier M, Siedler C, Sinnwell C (eds) Bedarfsgerechte Digitalisierung von Produktionsunternehmen. Synnovating, Kaiserslautern, pp 37-52

Publisher's Note Springer Nature remains neutral with regard to jurisdictional claims in published maps and institutional affiliations. 